\title{
Interacting with In-Vehicle Systems: Understanding, Measuring, and Evaluating Attention
}

\author{
Kenneth Majlund Bach, Mads Gregers Jæger, Mikael B. Skov and Nils Gram Thomassen \\ Department of Computer Science, Aalborg University \\ Selma Lagerlöfs Vej 300, DK-9220 Aalborg East, Denmark \\ \{kennethmajlund, mads.jaeger\}@hotmail.com,dubois@cs.aau.dk, nilsgramthomassen@gmail.com
}

\begin{abstract}
In-vehicle systems research is becoming a significant field as the market for in-vehicle systems continue to grow. As a consequence, researchers are increasingly concerned with opportunities and limitations of HCI in a moving vehicle. Especially aspects of attention constitute a challenge for in-vehicle systems development. This paper seeks to remedy this by defining and exemplifying attention understandings. 100 papers were classified in a two-fold perspective; under what settings are in-vehicle systems evaluated and how is driver attention measured in regard to in-vehicle systems HCI. A breakdown of the distribution of driving settings and measures is presented and the impact of driver attention is discussed. The classification revealed that most of the studies were conducted in driving simulators and real traffic driving, while lateral and longitudinal control and eye behaviour were the most used measures.
\end{abstract}

\section{Author Keywords}

In-vehicle systems, IVS, attention, literature classification, test track, driving simulator, measures, and driving settings.

\section{INTRODUCTION}

The in-vehicle systems (IVS) market has grown by a factor ten during the last generation [6]. In-vehicle systems now include embedded mini computers, navigation systems and televisions to name a few. Car manufacturers do not expect this development to stagnate and as Broy [6] states, the next generation will bear witness to an exponential growth of the in-vehicle systems domain.

The environment for in-vehicle system interaction is highly dynamic and interactive, and criteria regarding usability, learning ability, efficiency, memorization, error handling and satisfaction, have been extended also to comprise the requirement that driver distraction must be avoided. Wheatley [31] describes the driving context as a physically variable environment in terms of noise, light levels and space availability that is unpredictable by nature. Hence, the primary task is subjected to a high

(c) The Author 2009.

Published by the British Computer Society visual load with variable cognitive load, leaving only whatever resources remain for secondary task interaction.

Avoiding distraction and attention deficits in the driving task is the predominant challenge in in-vehicle systems development and as such an in-vehicle system should aim at taking the fewest resources from the driver. Attention to the primary task has always been an important issue in car manufacturing and car engineers have for the most part been able to come up with solutions that do not demand (visual) attention; throttle control, brakes, gear shift lever, clutch, etc. Traditional sources of internal distraction such as conversations with passengers, eating, drinking, lighting a cigarette, etc. [27] have now been supplemented with interaction with more or less elaborate information systems. This makes driver attention and appropriate secondary task interaction design as topical as ever.

While these systems are all useful in one or more important ways, they also conspire to an increasing load on the driver's attention resources since eyes and mind also are engaged away from the road and hands are employed elsewhere than on the wheel. This raises the concern that in-vehicle systems tend to become a safety risk to the driver, not to mention potential passengers and other drivers, as it is widely accepted that drivers engaging in visually and/or manually complex tasks tend to be more involved in accidents [16]. Because of the thought-provoking relationship between car accidents and in-vehicle system usage, the rapid development of invehicle systems is associated with an increasing scepticism (see e.g. [4, 22, 24, 25]). Attention is a concept that cannot be neglected when dealing with invehicle systems and understanding attention will be a tremendous help when contemplating, designing and evaluating in-vehicle systems.

The objective of this paper is to deliver an understanding of attention by defining the concept and by presenting specific findings on attention from the literature. To this end, further insight into the literature on attention is needed. Green [10] stresses the need for research studies gathering information on the impact of in-vehicle system usage while driving, particularly the role of driver attention in order to organize models that engineers can apply. According to Katz et al. [14], the foundation for carrying out research studies about attention is to establish frameworks for measurements - what, why, and how. Thus, a second objective of this paper is to provide such a framework. The framework will be based on two important factors for understanding and evaluating attention in in-vehicle systems, namely a) to what extent 
do attention related studies include the driving element and $b$ ) which measures are used to determine the presence and impact of attention. The result of this classification of attention related studies according to these two categories will carry with it a much needed overview of the most commonly used settings and measures.

\section{DRIVER ATTENTION AND DISTRACTION}

Attention spans several dimensions suggesting different types of scenarios and measures for evaluation of invehicle systems in order to comply with the driving and avoiding in-vehicle interaction caused attention problems. The below listed concepts and definitions will serve as a conceptual framework when presenting the approaches taken in existing research to measure and discuss attention in relation to in-vehicle systems.

Basically, Eysenck defines attention as the human's ability to concentrate on certain objects and allocate processing resources accordingly [8]. It can be seen as a telescope with which we point at things around us to make them stand out, thus when we place our attention on something, we ignore others. Although we try to devote attention to several things at the same time (designated divided attention), our ability to do so is limited. Kahneman [13] explains that people do have some control over the allocation of mental capacity of attention, which principally is affected by two factors: (a) intention and experience, which refers to the policy of giving higher priority to objects, which we are more interested in or familiar with and (b) evaluation of demands, which refers to our ability to evaluate the demands on capacity when there are several things around us, and give attention to the ones who need immediate attention or the ones who require lower capacity to handle. In a mobile environment dynamic objects often obtain the human's attention over static objects or an object that is currently paid attention to [13]

Distraction can be defined as anything that somehow takes away attention from the primary task. In the case of driver distraction, this is anything that takes the driver's attention away from the driving task. As stated by Green [11], the use of the notion of distraction to categorize vehicle crashes embraces everything from bees in cars to noisy children in the back seat to billboards with racy images. However, to form a framework for evaluation and measurement of attention and distraction, a more applicable designation of the concepts is needed.

Driver distraction can manifest itself in several ways [28]. The withdrawal of attention from the driving scene is the most commonly mentioned. According to Brown's [5] classification, withdrawal of attention can be divided into two types; general and selective. A general withdrawal of attention refers to an insufficient perception, typically visual, of the driving information. This can be due to eye glances away from the road scene, also known as eyesoff-the-road distraction. Normally drivers depend heavily on the visual perception on the driving task. According to Seppelt and Wickens, 90\% of the feedback the driver gets from driving is visual [21]. However, other sources of information from the physical environment, such as auditory or tactile feedback, need to be collected for safe driving. In-vehicle tasks will compete for the attention resources if the primary and secondary tasks draw on the same perceptual resource. Thus, two tasks that require the same kind of perceptual attention are more difficult to concurrently execute than two task that require attention of two different perception channels, e.g. visual and auditory [32]. As a consequense, Wickens and Hollands suggest that perceptual resources needed for secondary task interaction can be distributed over multiple senses, to mitigate decline in primary task performance [32].

A selective withdrawal of attention (corresponds mindoff-the-road distraction by Green [12]) seems to be an insidious type of distraction, because it deals with mental processing, e.g. perceptual interpretation, memory processes, decision selection, or decision execution, which requires attention and may reduce the total amount of attention capacity considerably [12]. This is the kind of attention deficits commonly associated with daydreaming, conversing with other passengers or talking on the phone, and can lead to a selective filtering of information based on expectations rather than the actual situation [28]. The concept is defined as inattention blindness, referring to the phenomenon where drivers fail to "see" an object in the driving environment, though they are looking directly at it [26]. Inattention is characterized as a shift of attention away from the driving task for noncompelling reasons, where distraction is a shift of attention for compelling reasons [19].

Another form of distraction described by Tijerina [28] is biomechanical interference or mechanical interference which refers to when the body shifts out of the neutral driving position, e.g., leaning to see something or taking the hand off the steering wheel to manipulate a device. The interference can degrade the driver's ability to execute driving manoeuvres and thereby constitutes safety risks.

A topic that is often mentioned in relation to attention and distraction is workload, which by Strayer et al. [20] is defined as the amount of processing resources used per time unit, for task performance. For this matter two concepts are pointed out; overload and underload. Overload occurs when a secondary task, typically a task not related to driving, makes exclusive use of one or several processing modalities, i.e. mental, perceptual or motor mechanical, which are requisites for the primary task of driving [17]. In-vehicle systems are one of the culprits regarding driver overload, because the interaction with the systems to a substantial extent draws on the same resources as the driving task. Whereas most of the literature regarding in-vehicle systems and workload is concentrated on the problem of overload, there is also a point being made about driver underload [7]. This is primarily the case for automated driving assistance systems, since they may result in drivers being over reliant and lower the driver's level of attention, effectively decreasing his/her chance of detecting dangers in time to do anything about them [18].

As presented, attention is not easily defined or restricted to a single concept. However, in our classification of literature we have opted not to distinguish between the 
individual papers' definitions of attention. Instead we aim to provide an overview of how attention evaluations are conducted and measured and in this regard the individual papers' interpretations of attention will not be included.

\section{CLASSIFICATION FRAMEWORK}

The papers reviewed in this paper have been selected from a larger research study on in-vehicle systems interaction. This study used a rather rigorous approach, which can be found described in detail in [1]. The study consisted of a review of 289 papers which were all read by two of the authors. A data sheet with information such as title, author, journal, publisher, year of publishing, number of pages, etc. was created for each of the papers, and in this process, each data sheet was augmented with an abstract and a set of topics. These topics have served as a basis for selecting appropriate papers for this classification of attention related literature. From the 289 papers, we retrieved the papers that had been flagged with topics that indicated relevance for the focus of this classification (e.g. attention overload, attention underload, distraction, focused attention, divided attention, or inattention blindness), which resulted in 181 papers. These 181 papers were then subjected to a series of eliminations. First we sorted out papers that did not present any study (including experiment and evaluation) with attention related issues. Second, we removed "duplicate experiment papers", to make sure an experiment only existed once in the papers. This narrowed down the list to the final 100 papers used in this classification. These are presented in the appendix of reviewed attention papers. We will distinguish appendix papers from references by denoting them by their index in italic font style, i.e. [10] refers to the paper with index 10 in the appendix list, and [10] refers to the paper with index 10 in the reference list.

\section{Driving Settings}

Based on our own previous studies [2,3], we define four driving settings that are characterized by the degree to which they incorporate driving elements and is used as general term for the conditions being used for attention research. These driving settings have been selected and defined specifically for this paper and have been constructed based on initially reading. While the driving settings are discrete it should be noted that some of the driving settings could be divided into multiple driving settings and that the line between them can be considered fluid. However, the driving settings are based on their individual and distinct relation to the driving activity and in this regard we believe they are useful for the classification.

\section{No Driving}

The no driving setting are used in studies that do not involve a scenario that tries to resemble a driving activity (though some seek to approximate the attention level of driving, for instance by replicating isolated elements from driving). An experiment involving reaction times is a typical example, where participants could for instance be asked to push a button when an indicator lamp comes alight. As these elements only serve to mimic a secluded (and in itself artificial) part of the driving task, we have chosen to place such studies in the no driving category.

\section{Simulated Driving}

Simulated driving refers to studies conducted in a socalled driving simulator. Driving simulators can be of varying qualities and fidelity. Stanton [23] stated that the realism of a driving simulation should be measured by its degree of physical and functional fidelity. Physical fidelity refers to the degree to which the driving simulator looks like the real environment and functional fidelity, the degree to which the driving simulator behaves like the real environment. Hence, there exist low-fidelity, medium-fidelity and high-fidelity driving simulators in regard to the fulfilment of the two issues that apply to creating realism in a driving simulator. We will not distinguish between the various degrees to which a given simulation is realistic. Therefore, any experiment that uses a setup that can be considered a simulation of driving is placed in this category.

\section{Controlled Driving}

Controlled driving refers to real driving that takes place in a real car, but where the driving takes place in a controlled environment with variables that can be adjusted for the purpose of the driving session. This is typically driving that takes place on a closed circuit or test track where one is able to control the amount of traffic or be specific about the way the participant should drive the car. If the driving featured in a study is subjected to a controlled environment, it will be placed in this category, regardless of the degree of realism.

\section{Real Traffic Driving}

Real traffic driving is limited to studies that take their research into the actual and intended use context. Real traffic driving has characteristics that make the studies less controllable and furthermore this setting provides some safety-critical/ethical issues that may make it hard to conduct experiments, especially in regards to attention. Real traffic driving is characterized by autonomous agents such as other drivers or soft road users who are uncontrollable and unpredictable. When placing a paper in this category, we have opted not to consider properties such as traffic density or the difficulty of the road used for the experiment. While some studies feature real traffic driving that is somewhat controlled, for instance by placing a lead vehicle in front of the evaluation vehicle, we have still placed these studies in this driving setting.

The descriptions of the driving settings make it obvious that they differ in realism and control and that these parameters are difficult to reconcile. These driving settings will serve as one of our classification categories, to investigate the relationship between the driving settings and the research purposes. The other category we will classify the papers by concern the attention measures used in the studies.

\section{Attention Measures}

The above presented definitions of attention and distraction (and variations of these concepts) outline some of the properties of attention measures. As described, a general withdrawal of attention refers to an 
insufficient perception, typically visual and manifests itself in both degraded vehicle control and degraded object and event detection. This suggests a focus on indicators or metrics of driving performance and eye glance behaviour for measuring this kind of driver distraction. The selective withdrawal of attention is however more difficult to determine, since it manifests itself in degraded object and event detection, while vehicle control remains largely unaffected. This somewhat limits the ways to measure this kind of distraction directly; however some indirect measurements can be employed.

According to Green [12], the attention measures to investigate the safety-relevant distraction effect induced by secondary tasks can be divided into four categories; primary task performance, secondary task performance, physiological measures and subjective assessments. In addition a category for eye glance behaviour is included because of the importance visual perception has for driving a vehicle. The most important and frequently used measures under these categories are pointed out by Green [12]; Katz, et al. [14]; Tijerina [28]; and Tsimhoni, O., Yoo, H. and Green, P. [29], and are summarized below. We will use these categories to classify the papers according to what attention measures they use.

\section{Primary Task Performance}

Concerning aspects of vehicle control, this category is closely related to attention and distraction, since lack of vehicle control can degrade driving performance due to changes in the driver's mental and perceptual attention capacity. The primary measures in this category are: lateral control (e.g. lane excursions, steering wheel input), longitudinal control (e.g. speed maintenance, break pedal application, throttle angle deviation), car following performance (e.g. time-to-collision, distance to a leading car), and driver reaction (e.g. time spent on adopting to an unexpected incident).

\section{Secondary Task Performance}

The secondary task performance category includes all the performance measures related to secondary task interaction, i.e. all tasks which entail manipulation of an in-vehicle system while driving. The primary metrics in this category are task effectiveness (e.g. interaction errors, task completion) and task efficiency (e.g. task completion time using biomechanical interference measures, such as hands-off-wheel time or eyes-off-the-road time)

\section{Eye Glance Behaviour}

Driver eye glance behaviour is a very relevant measure to be taken into account because of the impact of (lack of) visual attention on the driving task. The primary metrics in this category are: eye glance frequency, eye glance duration, and eye scanning patterns (e.g. measurements of where the driver looks, for instance by means of eye tracking or electrooculography).

\section{Physiological Measures}

In the sense that the human body is a mirror of the internal conditions, physiological measures can serve as indicators for workload, including stress level and attention capacity. The primary measures are: electrocardiogram (e.g. heart rate and blood pressure variability), body temperature, skin conductance, respiration and electromyogram (e.g. muscle contraction).

\section{Subjective Assessments}

Subjective assessments of workload or stress can be useful to discover participants' perceptions of the workload and attention capacity before, during, and after an evaluation. There are a number of workload ratings; however SWAT and NASA-TLX are the commonly used techniques in the in-vehicle systems genre [14].

\section{RESULTS}

Results are summarized in table 1. Lateral control is the most commonly used attention measure, followed by longitudinal control with representation in $41 \%$ and $35 \%$ of the papers respectively. Car following performance and driver reaction times are used in $16 \%$ and $30 \%$ of the papers. Most of the primary task measures are obviously only used in driving settings that involve either simulated, controlled or real traffic driving; however measures of driver reaction times are also present in some of the studies conducted with no driving. In addition to this, Table 1 shows that driving reaction is the most used primary task measure used in studies with no driving or controlled driving, and is also one of the most commonly used measures across driving settings. This can be explained by the fact that a considerable amount of the studies that include driver reaction times as a measure are conducted in laboratories or on test track facilities focusing on driver reaction while performing various secondary tasks (e.g. [27, 44, 54]). Secondary task effectiveness is the most frequently used measurement with representation in $44 \%$ of the papers. This measurement typically refers to the number of errors in the particular task execution, like incorrect answers to logical or memory tasks (e.g. $[3,13,21])$ and interaction errors with the in-vehicle system evaluated (e.g. $[13,26$, $60]$ ), etc. Task efficiency is used in $21 \%$ of the papers and is often constituted by task completion times using a data $\log$ (e.g. [50]) or some of the other measures, such as eyes-off-the-road-time (e.g. $[6,87$, 90]). Task effectiveness is well-distributed over the four driving settings; however it constitutes a relatively larger portion with no driving than in the other settings, which is due to a higher representation of research with a focus on secondary task performance, like the aforementioned examples, which do not necessarily imply driving tasks. However, task efficiency is in many papers related to the driving performance (e.g. [12, 23, 39]) and it is not as popular in no driving as the task effectiveness measure. 
Interacting with In-Vehicle Systems: Understanding, Measuring, and Evaluating Attention

\begin{tabular}{|c|c|c|c|c|c|}
\hline & & $\begin{array}{c}\text { No } \\
\text { Driving } \\
(\mathrm{N}=16)\end{array}$ & $\begin{array}{l}\text { Simulated } \\
\text { Driving } \\
(\mathrm{N}=52)\end{array}$ & $\begin{array}{l}\text { Controlled } \\
\text { Driving } \\
(\mathrm{N}=7)\end{array}$ & $\begin{array}{l}\text { Real Traffic } \\
\text { Driving } \\
(\mathbf{N}=30)\end{array}$ \\
\hline \multirow{4}{*}{ 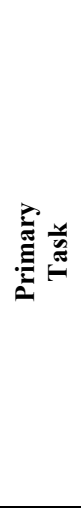 } & $\begin{array}{l}\text { Lateral Control } \\
\qquad(\mathrm{N}=\mathbf{4 1})\end{array}$ & 74 & $\begin{array}{c}3,4,12,15,16,34,35 \\
39,41,42,43,45,46 \\
47,48,49,51,52,53 \\
57,72,73,78,84,88 \\
89,90,92,95,97\end{array}$ & 1,85 & $\begin{array}{c}9,11,14,23,29,50 \\
94,100\end{array}$ \\
\hline & $\begin{array}{c}\text { Longitudinal Control } \\
\quad(\mathbf{N}=35)\end{array}$ & 74 & $\begin{array}{c}4,15,16,20,34,35 \\
39,42,45,49,51,52 \\
53,78,79,84,89,91 \\
94\end{array}$ & $1,27,55,85$ & $\begin{array}{c}9,11,23,29,50,64 \\
66,68,71,79,94,100\end{array}$ \\
\hline & $\begin{array}{c}\text { Car Following Performance } \\
(\mathrm{N}=16)\end{array}$ & & $\begin{array}{l}16,20,39,51,52,73 \\
78,79,82,83,84,89\end{array}$ & 44 & $40,71,79$ \\
\hline & $\begin{array}{l}\text { Driver Reaction } \\
\qquad(\mathbf{N}=\mathbf{3 0})\end{array}$ & $8,17,32,37,54,56$ & $\begin{array}{c}3,5,8,22,33,36,45 \\
47,57,75,80,83,84 \\
88,91,92,97\end{array}$ & $1,27,28,44,55$ & $8,23,39,60$ \\
\hline \multirow{2}{*}{ 离 } & $\begin{array}{l}\text { Task Effectiveness } \\
(\mathrm{N}=44)\end{array}$ & $7,13,25,38,54,56,77$ & $\begin{array}{c}3,4,5,6,21,22,24 \\
33,39,41,42,43,48 \\
53,54,72,75,81,83 \\
88,89,97\end{array}$ & $27,44,85$ & $\begin{array}{c}6,9,11,18,23,26,40 \\
50,59,60,63,64,65\end{array}$ \\
\hline & $\begin{array}{c}\text { Task Efficiency } \\
(\mathbf{N}=\mathbf{2 1})\end{array}$ & $8,38,74$ & $\begin{array}{c}6,8,12,21,39,43,53 \\
58,89,90\end{array}$ & 85 & $\begin{array}{c}6,8,11,14,23,50,59 \\
67,76,87\end{array}$ \\
\hline \multirow{5}{*}{ 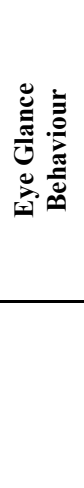 } & $\begin{array}{l}\text { Eye Glance Frequency } \\
\qquad(\mathbf{N}=\mathbf{2 8})\end{array}$ & 38,54 & $\begin{array}{c}10,12,41,46,47,53 \\
62,69,73,79,81,89 \\
90\end{array}$ & 1,85 & $\begin{array}{l}9,14,23,59,63,64 \\
65,66,68,76,79,87\end{array}$ \\
\hline & $\begin{array}{l}\text { Eye Glance Duration } \\
(\mathbf{N}=27)\end{array}$ & $38,54,70,96,99$ & $\begin{array}{c}10,12,41,46,53,62 \\
69,73,79,81,83,89 \\
90,95\end{array}$ & 1,85 & $\begin{array}{c}14,23,59,64,65,79 \\
87\end{array}$ \\
\hline & $\begin{array}{c}\text { Eye Scanning Patterns } \\
(\mathrm{N}=16)\end{array}$ & 38,54 & $24,69,73,83,97$ & 85 & $\begin{array}{c}14,19,29,64,65,76 \\
79,86\end{array}$ \\
\hline & $\begin{array}{l}\text { Physiological Measurements } \\
\qquad(\mathrm{N}=10)\end{array}$ & & $15,16,69,97$ & & $19,30,50,59,68,94$ \\
\hline & $\begin{array}{l}\text { Subjective Assessments } \\
(\mathbf{N}=\mathbf{3 0})\end{array}$ & 8,98 & $\begin{array}{l}3,4,8,15,16,22,42 \\
43,47,48,51,53,58 \\
88,89,92,93,95,97\end{array}$ & $1,2,44$ & $\begin{array}{c}8,9,14,23,29,31,59 \\
61,63,94\end{array}$ \\
\hline
\end{tabular}

Table 1. Classification of attention measures distributed over driving settings. Numbers refer to indexes in the appendix of reviewed papers. $\mathrm{N}$ indicates the number of unique papers in the respective categories

Eye glance frequency and eye glance duration measures are used in $28 \%$ and $27 \%$ of the papers, whereas eyescanning patterns are measured in $16 \%$ of the papers. In most papers both frequency and duration measurements are used complementary to each other (e.g. [10, 38, 65]). Eye scanning pattern data is in most papers collected with special made eye tracking equipment (e.g. [76, 79, 86]).

Physiological measures are used in $10 \%$ of the papers and thus, the least used measures. Electrocardiogram is the predominant of these measures and it is used in all studies using physiological measures, whereas other physiological measurements, such as body temperature (see [69]), skin conductance (see [30, 68, 69, 94]), respiration (see [30, 69]), and electromyogram (see [30]) are used only by a single or few papers. The physiological measures are used in connection with simulated driving and real traffic driving and serve to detect changes in driver attention capacity and driver workload (e.g. $[15,50,97])$.

Subjective assessments of workload and attention capacity are used in $30 \%$ of the papers, especially in connection with simulated driving and real traffic driving. An array of different assessment techniques and questionnaires is used in the papers; however the NASATLX assessment is the most commonly used (e.g. [42, 62, 91]).

\section{DISCUSSION AND CONCLUSION}

In this section, we will try to establish an understanding of the concept of driver attention by drawing out key elements from the classification and exemplifying these with qualitative findings from the classified papers.

\section{Understanding Driver Attention}

Green stresses the urgent need for research studies on the impact of in-vehicle system usage while driving [10]. This notion is in line with much of the research that aims to understand the field of in-vehicle systems and should be used in development of standards, guidelines, rules and methods that can serve in the engineering phase.

A common example of studies done for understanding is research studies of cell phones' impact on driver distraction and driving performance $[3,27,29,56,67,75$, 80 , 86]. It is well established that cell phone usage impairs the driving performance significantly. Research found that drivers engaging in cell phone conversation using either a hand-held or hands-free device, are more 
than twice as likely to miss traffic signals and often fail to see billboards and other signs, than when they are not distracted by the cell phone conversation [81]. This indicates that conversing on a cellular phone causes inattention blindness disrupting the driver's visual attention to the driving environment. In addition drivers react more slowly to changes in traffic patterns, when they are engaged in a cell phone conversation, which can be designated as change blindness $[60,81]$. It is needless to say, that these driver states are insidious to driving safety and several studies and statistics lay evidence to this claim $[38,63,67,80]$. A comprehensive study of accident reports found that $24 \%$ of the 669 individuals involved in accidents during the study period had used their cell phones during the 10 minutes preceding the accident [67].

Several studies on cell phone induced distraction deal with the relationship between the effects of biomechanical interference, such as dialling and holding the phone, and the mental processing of information while conversing (e.g. $[3,56,60,80,92])$. It is well stated, that the psychomotor aspects of cell phone use per se only constitute a minor factor in the deterioration of driving performance compared to the verbal task. In some studies passive verbal tasks, such as listening to the radio were not found to interfere with the driving task, while conversation with a hand-held or a hands-free cell phone, including listening to a partner and generating responses did disrupt driving performance [39, 80]. In regard to cell phones, the content of the conversation is far more important for driving and driver distraction than the type of telephone. The more difficult and complex the conversation is the greater the possible negative effect on driver distraction [60, 92].

Although the selective withdrawal of attention, or mindoff-the-road, seems to be the more insidious type of attention failures, the general withdrawal, or eyes-off-theroad, seems to be the more common. Because of the importance of sight in the driving task, information on the driver eye glance behaviour is gathered, such as numbers of glances and fixation times, in studies of a variety of driving tasks (e.g. $[38,41,46,54])$. Some of the results include, that on average, a driver spends approximately 0.78 seconds $(\mathrm{SD}=0.65)$ and 1.26 glances $(\mathrm{SD}=0.40)$ to read a speedometer and 1.10 seconds $(\mathrm{SD}=0.30)$ to check the left mirror [46]. Other studies, [70, 99] suggest that drivers are reluctant to go without roadway information for more than 2 seconds (dubbed the "2second rule"). Analysis of driver eye glance behaviour indicates that total eyes-off-the-road durations of greater than 2 seconds significantly increase crash risk whereas eye glance durations less than 2 seconds do not significantly increase risk relative to normal, baseline driving [38]. Research results as these have led to a set of safety guidelines for designing in-vehicle systems with focus on visual attention, for instance that an average of 2.7 glances and a total of 4.10 seconds fixation time are the maximum values allowed when driving at $30 \mathrm{~km} / \mathrm{h}$ [46], or that glances to displays should not be longer than 2.5 seconds [1] or 1.5 seconds [96]. Even though the research results and guidelines differ, they clearly point to the fact that only a limited amount of information can be conveyed safely to the driver. As a result, any design of new in-vehicle system must not overload the driver perceptually. Thus, if in-vehicle systems interaction can be designed such that it has only few glances and low fixation times, or simply has no interaction induced visual demands; it may very well increase safety while driving.

There is a substantial number of studies examining possible interaction technologies for reducing the visual perceptual load. In the literature speech recognition and text-to-speech technology are pointed out as possible remedies to reduce visual demands (e.g. $[13,23,29,86$, 100]). A common assumption pertaining to speech technology for in-vehicle systems is that speech-based interactions do not distract drivers, because drivers are not required to take their eyes off the road or their hands off the steering wheel. Studies [13, 23, 29] have shown benefits in such an "eyes-free, hands-free" method of interaction for in-vehicle systems in empirical terms. Nevertheless, voice-based interactions are not effortless and they have the potential to place cognitive demands on drivers with mind-off-the-road as a consequence [86, 100]. Although speech-based interaction offers promising alternatives to visual-based interfaces, the opinions are divided, since growing evidence suggest that systems with speech technology impose cognitive load on drivers that can affect driving performance.

Another approach pointed out as an eyes-free method of interaction is gestures as illustrated by Alpern and Minardo [4]. Where existing gesture-interface research has centred on controlling the user's primary task, this study explores the use of gestures to control secondary tasks while driving. In a wizard of $\mathrm{Oz}$ based driving simulator experiment, test participants performed entertainment tasks, (e.g. find a song, search presets, adjust volume) with both a gesture interface on the windshield and a standard radio installed in the simulator. Drivers in the gesture condition made fewer driving errors than with the physical interface but the difference was not significant. In qualitative interviews after the experiment, the participants preferred the gesture interface over the radio, because they could keep eyes and attention on the driving task and did not have to reach and touch anything, and could be less precise with the gestures. While these results are far from conclusive, they suggest gesture interfaces can be used as safely as a physical radio and seems to be a viable alternative for completing secondary tasks in the car. More research is needed to identify the potential and limitations of gestures as a secondary task interaction technology.

\section{Evaluating Driver Attention}

Many of the studies were conducted in simulated driving $(51 \%)$ and this tendency could be explained by the rapid start-up phase that in-vehicle systems development is subjected to. Moreover this driving setting offers a number of benefits; it provides precise control over all elements to create identical and repeatable scenarios. Furthermore, simulated driving allows researchers to analyze risky scenarios without endangering a participant. Therefore, simulated driving is often used to design and 
evaluate scenarios that would not be feasible or ethical in real driving, whether it is in a controlled driving setting or in a real traffic driving setting. Hence, simulated driving is beneficial in areas where controlled driving and real traffic driving are limited; making simulated driving a popular option in safety research programs [98].

Controlled driving studies represent a step closer to real world driving. How big a step depends on the nature of the course and the research protocol. An interesting finding within this driving setting was the fact that only seven studies were conducted in controlled driving. This gives rise to the possibility that test tracks or other closed circuits are not considered to be worth the effort or simply do not bring enough added value along. Investigating the seven studies reveal that the geographical place is limited to only five different places; two of them related to universities. This seems to indicate that experiments in controlled driving is troublesome to arrange compared to the added value in reference to simulated driving or that the controllability does not make it up for the safety issues that real driving involves. The papers do not argue for the choice of controlled driving, and this raises the question, whether this driving setting really is worth the hassle? Whatever the case, this finding sets the stage for an examination of the three driving settings that involve some version of driving. However, a critical issue in this regard is the ability to create comparable scenarios in simulated driving and real driving.

The limitations in simulated driving and controlled driving do not imply that these methods cannot be used to gather useful information. As stated by Goodman et al. [7], each of them has a place in safety research, particularly as a means to minimize safety hazards in exploratory research. However, it is important not to be blind to the limitations of the methods and the need for validation by means of studies in real traffic. The latter driving setting provides the greatest degree of realism. Hence, research in real traffic driving has a high representation of observational studies (e.g. $[18,26,79]$ ) because real traffic driving provides the driver with real driving task demands.

\section{Measuring Driver Attention}

Safety and attention cannot be measured directly, although indirect measures are applied. Table 1 shows that primary task measures such as lateral control (e.g. measurement of lane keeping performance) and longitudinal control (e.g. speed maintenance) are commonly used measures of driver distraction related to secondary task interaction (e.g. $[3,12,34,39,44]$ ). Therefore, it is quite common to make inferences, such that higher driver workload when interacting with an invehicle system implies greater lateral movement and more frequent lane exceedences. It is interesting to note that a measure such as the number and length of lane exceedences during in-vehicle interaction is not considered primarily safety-relevant by everyone. Some argue that if there is no other traffic users nearby, if the lane exceedence is small or of short duration, or if the lane exceedence or speed reduction reflects the driver's strategy for compensation and reducing workload during concurrent task execution, there is no safety implication at all $[16,50]$.

This is an interesting line of reasoning, because it contradicts accident research and statistics that indicate that distraction related crashes are more likely during good conditions, i.e. in daytime, good weather, moderate traffic density, when the drivers think everything is fine [11]. Therefore, it seems injudicious to conduct comparative studies of different in-vehicle systems, find that one induces substantially more lane exceedences and still declare such results irrelevant unless there happened to be a crash hazard exposure.

Driver eye glance behaviour measures are often used, primarily because of the importance of vision in driving $[1,24,38,41,53]$. Eye glance behaviour is often measured by the glances a driver makes to a specific invehicle system while driving, i.e. the number of times the driver glances away from the scene view to look at the display and the length of these glances [1]. Eye fixation (when the eyes can be said to dwell on something), typically glances over 0.5 seconds, is often used as an indicator for to which objects the driver's attention is directed [24].

While measures of eye glance behaviour, in association with lateral control and longitudinal control, are used as detectors of general withdrawal of attention, it does not necessarily say anything about the selective withdrawal of attention that might be associated with in-vehicle systems. This is especially the case for in-vehicle systems that do not demand visual resources, such as speechbased interaction systems. During interaction with these systems, the driver's eyes can be kept on the road and hands on the steering wheel, serving the fundamental conditions for lane keeping and speed maintenance; however the mind might be elsewhere than on the driving task. Therefore other measures, such as reaction time and car following performance are used, as a way to measure the selective withdrawal of attention, by determining the driver's ability to react to external stimuli while interacting with the in-vehicle system. As table 1 illustrates, studies with reaction time are typically conducted in environments, where driving conditions, if any, such as road traffic, traffic lights, signs, and pedestrians are non-existent or controlled.

The results of the classification indicate that, whether how people drive, how to measure driver attention or whether it concerns causal relationships between invehicle systems and driving performance, much of the research contribute to an understanding of a fairly new research field. Katz, et al. [14] stress the importance of agreeing on a set of measures as the most important and predictive ones to be used as guidelines for engineers. Without agreement, engineers cannot verify claims that a specific design is safer to use or more suited for secondary task interaction. In this regard, different rules and guidelines have been developed to accommodate engineers. Although researchers roughly agree on a set of metrics to measure attention by, they do not necessarily agree on how the rules should be defined. For instance, it 
is interesting that widespread measures, such as lateral control and longitudinal control are not outlined in the literature. In addition, Green [25] introduced the 15 second-rule that states that the time allowed for completing a navigation system task involving manual controls and visual displays when the task is performed when not in motion, should be 15 seconds. However, Tijerina et al. [85] have disputed the applicability of this rule, since the plausibility of accurately determining whether a device adheres to the rule is limited. Furthermore, Salvucci states that the rule ignores many clearly important factors such as conflicting modalities between interaction and driving [74].

\section{FURTHER WORK}

Based on the above classification and discussion of the research into attention measures and driving settings for in-vehicle systems, a need for further research presents itself.

Though most of the studies realize the need for innovation or enhancement of the interaction techniques available for in-vehicle systems, there are very few attempts to redeem this situation. Furthermore, the results have stressed that research on which driving setting is the more appropriate for in-vehicle system studies is needed, which demands a direct pair-wise comparison of driving settings. In this regard it is especially interesting whether there is added value in using controlled driving over simulated driving, or if the problems associated with this kind of evaluation outweighs the extra realism.

\section{REFERENCES}

1. Bach, K. M., Jæger, M. G. and Thomassen, N. G. (2007). Driving - A Literature Review. Department of Computer Science, Aalborg University

2. Bach, K. M., Jæger, M. G., Skov, M. B., and Thomassen, N. G. (2008) Evaluating Driver Attention and Driving Behavior: Comparing Controlled Driving and Simulated Driving. In Proceedings of HCI 2008 The 22st British HCI Group Annual Conference (BCS-HCI'08), Liverpool, United Kingdom, pp. 193-201

3. Bach, K. M., Jæger, M. G., Skov, M. B., and Thomassen, N. G. (2008) You Can Touch, but You Can't Look: Interacting with In-Vehicle Systems. In Burnett, M. and Costabile, M. F. (Eds.) Proceedings of the Human Factors in Computing Systems (CHI'08), Florence, Italy, ACM Press, pp. 11391148

4. Barrot, J. (2001). Road Safety: Results from the transport research programme. EXTRA consortium for DG Energy and Transport.

5. Brown, I. (1994). Driver fatigue in Human Factors, Vol. 36, Issue 2, 298-314. Human Factors and Ergonomics Society.

6. Broy, M. (2006). Challenges in Automotive Software Engineering in ICSE. ACM Press.

7. Carsten, O. and Nilsson, L. (2001). Safety Assessment of Driver Assistance Systems in EJTIR, Vol. 1, No. 3, Pages 225 - 243. European Journal of Transport and Infrastructure Research.

8. Eysenck, M. W. (2001). Principles of cognitive psychology (2nd ed.).. Psychology Press.

9. Goodman, M., Bents, F. D., Tijerina, L., Wierville, W., Lerner, N. and Benel, D. (1998). A Review of Human Factors Studies on Cellular Telephone Use While Driving in An investigation of the safety implications of wireless communications in vehicles (Ch. 5). Accessed $11^{\text {th }}$ June 2009 and online available [http://www.nhtsa.dot.gov/people/injury/research/wireless/]

10. Green, P. (1996). Customer Needs, New Technology, Human Factors, and Driver Science Research for Future Automobiles in Journal of the Society of Mechanical Engineers. University of Michigan Transportation Research Institue (UMTRI).

11. Green, P. (1999). The 15-Second Rule for Driver Information Systems. Intelligent Transportation Society of America

12. Green, P. (2001). Variations in Task Performance Between Younger and Older Drivers: UMTRI Research on Telematics in Association for the Advancement of Automotive Medicine Conference on Aging and Driving, Southfield, Michigan.

13. Kahneman, D. (1973). Attention and Effort. Prentice Hall.

14. Katz, S., Fleming, J., Green, P., Hunter, D. and Damouth, D. (1997). On-the-Road Human Factors Evaluation of the AliScout Navigation System (Technical Report UMTRI-9632). Ann Arbor, MI: The University of Michigan Transportation Research Institute.

15. Kjeldskov, J. and Graham, C. (2003). A Review of Mobile HCI Research Methods in Proceedings of the 5th International Mobile HCI 2003 conference. SpringerVerlag.

16. Klauer, S. G., Dingus, T. A., Neale, V. L. and Sudweeks, J. D. (2006). The Impact of Driver Inattention on NearCrash/Crash Risk: An Analysis Using the 100-Car Naturalistic Driving Study Data.

17. Liu, Y. (2001). Comparative Study of the Effects of Auditory, Visual and Multimodality Displays on Drivers in Ergonomics, 2001, Vol. 44, No. 4, Pages 425-442. Taylor \& Francis Ltd.

18. Norman, D. A. (2005). There is an Automobile in HCIs Future in Interactions, Volume 12, Issue 6, Pages 45-46. ACM Press.

19. Noy, Y. Ian (2006). Human Factors Issues Related to Driver Distraction From In-Vehicle Systems. Ergonomics Division, Transport Canada.

20. Patten, C. J.D., Kircher, A., Östlund, J., Nilsson, L. and Svenson, O. (2006). Driver Experience and Cognitive Workload in Different Traffic Environments in Accident Analysis and Prevention, Vol. 38 , Pages 887-894. Elsevier Ltd.

21. Seppelt, B. and Wickens, C. D. (2003). In-Vehicle Tasks: Effects of Modality, Driving Relevance, and Redundancy in General Motors Corporation. Aviation Human Factors Division, Institute of Aviation.

22. Sodhi, M., Reimer, B., Cohen, J. L., Vastenburg, E., Kaars, R. and Kirschenbaum, S. (2002). On-road Driver Eye Movement Tracking Using Head-Mounted Devices in ETRA 02 New Odeans Louisiana USA.

23. Stanton, N. (1996). Simulators: research and practice in Nuclear Safety. Taylor \& Francis.

24. Stanton, N. A. and Young, M. S. (2005). Driver Behaviour with Adaptive Cruise Control in Ergonomics, Vol. 48, No. 10. Taylor \& Francis Group.

25. Stevens, A. (2000). Safety of Driver Interaction with InVehicle Information Systems in Proceeding of the Institution of Mechanical Engineers - Part D - Journal of Automobile Engineering, Vol. 214, Issue 6, Pages 639-644. Professional Engineering Publising.

26. Strayer, D. L., Drews, F. A. and Johnston, W. A. (2003). Cell Phone-Induced Failures of Visual Attention During 
Simulated Driving in Journal of Experimental Psychology, Vol. 9, No. 1, Pages 23-32. American Psychological Association, Inc.

27. Stutts, J., Feaganes, J., Rodman, E., Hamlet, C., Meadows, T., Rinfurt, D., Gish, K., Mercadante, M. and Staplin, L. (2003). Distractions in everyday driving. AAA Foundation for Traffic Safety.

28. Tijerina, L. (2000). Issues in the Evaluation of Driver Distraction Associated with In-Vehicle Information and Telecommunications Systems. Transportation Research Center Inc.

29. Tsimhoni, O., Yoo, H. and Green, P. (1999). Effects of Visual Demand and In-Vehicle Task Complexity on Driving and Task Performance as Assessed by Visual Occlusion. University of Michigan Transportation Research Institue (UMTRI).

30. Verwey, W. B. (2000). On-line Driver Workload Estimation. Effects of Road Situation and Age on Secondary Task Measures in Ergonomics, Vol. 43, No. 2, Pages 187209. Taylor \& Francis Ltd.

31. Wheatley, D. J. (2005). Beyond the Desktop: And Into Your Vehicle in Development Consortium. CHI 2005.

32. Wickens, C. D. and Hollands, J. G. (2000). Engineering Psychology and Human (3. ed.). Prentice Hall.

33. Wynekoop, J. L. and Conger, S. A. (1990). A Review of Computer Aided Software Engineering Research Methods in Proceedings of the IFIP TC8 WG 8.2 Working Conference on The Information Systems Research Arena of the 90's.

\section{APPENDIX: REVIEWED ATTENTION PAPERS}

1. Aguiló, M. C. Fumero (2004). Development of Guidelines for In-Vehicle Information Presentation: Text vs. Speech. Faculty of the Virginia Polytechnic Institute and State University

2. Airaksinen, T., Aminoff, H., Byström, E., Eimar, G., Mata, I. and Schmidt, D. (2004). Automatic Parallel Parking Assistance System. Cognitive Science Program, University of Linköping.

3. Alm, H. and Nilsson, L. (1995). The Effects of a Mobile Telephone Task on Driver Behaviour in a Car Following Situation in Accident Analysis \& Prevention, Vol. 27, Issue 5 Pages 707-715. Elsevier Science Ltd.

4. Alpern, M. and Minardo, K. (2003). Developing a Car Gesture Interface for Use as a Secondary Task in CHI 2003: New Horizons. Human-Computer Interaction Institute (HCII), Carnegie Mellon University.

5. Amado, S. and Ulupinar, P. (2005). The Effects of Conversation on Attention and Peripheral Detection: Is talking with a Passenger and Talking on the Cell Phone Different? in Transportation Research Part F 8, 2005, Pages 383-395. Elsevier Ltd.

6. Baumanna, M., Keinatha, A., Kremsa, J. F. and Bengler, K. (2004). Evaluation of InVehicle HMI Using Occlusion Techniques: Experimental Results and Practical Implications in Applied Ergonomics, Vol. 35, Page 197. Department of Psychology, Chemnitz University in Applied Ergorn

7. Bellotti, F., Berta, R., Gloria, A. De and Margarone, M. (2002). Using 3D Sound to Improve the Effectiveness of the Advanced Driver Assistance Systems in Personal and Ubiquitous Computing, Vol. 6, Pages 155-163. Springer-Verlag London Ltd.

8. Bellotti, F., Gloria, A. De, Montanari, R., Dosio, N. and Morreale, D. (2005). COMUNICAR: Designing a Multimedia, Context-Aware Human-Machine Interface for Cars in Cognition, Technology \& Work, Vol. 7, No. 1, Pages 36-45. Springer.

9. Blanco, M. (1999). Effects of In-Vehicle Information Systems (IVIS) Tasks on the Information Processing Demands of a Commercial Vehicle Operations (CVO) Driver. Virginia Polytechnic Institute and State University.

10. Brookhuis, K., Winsum, W. van, Heijer, T. and Duynstee, L. (1999). Assessing Behavioral Effects of In-Vehicle Information Systems in Transportation Human Factors, Pages 261 272. Lawrence Earlbaum Associates, Inc.

11. Brown, D., Tickner, A. H. and Simmonds, D. C. V. (1969). Interference Between Concurrent Tasks of Driving and Telephoning in Journal of Applied Psychology, Vol. 53, No. 5, Pages 419-424. American Psychological Association.

12. Broy, V., Althoff, F. and Klinker, G. (2006). Designing for the End User: Short Papers: iFlip: A Metaphor for In-Vehicle Information Systems in AVI 06 Conference.

13. Cavedon, L., Weng, F., Mishra, R., Bratt, H., Raghunathan, B., Cheng, H., Schmidt, H., Mirkovic, D., Bei, B., Pon-Barry, H. and Scheideck, T. (2005). Developing a Mirkovic, D., Bel, B., Pon-Barry, H. and Scheideck, T. (2005). Developing a
Conversational In-Car Dialog System. Center for the Study of Language and Information, Conversational In-C
Stanford University.

14. Chiang, D. P., Brooks, A. M. and Weir, D. H. (2004). On the Highway Measures of Driver Glance Behavior with an Example Automobile Navigation System in Applied Ergonomics, Vol. 35, Pages 215-223. Elsevier Ltd.

15. Cnossen, F., Meijman, T. and Rothengatter, T. (2004). Adaptive Strategy Changes as a Function of Task Demands: A Study of Car Drivers in Ergonomics, Vol. 47, No. 2, Pages 218-236. Taylor \& Francis Group.

16. Cnossen, F., Rothengatter, T. and Meijman, T. (2000). Strategic Changes in Task Performance in Simulated Car Driving as an Adaptive Response to Task Demands in Transportation Research Part F 3, Pages 123-140. Elsevier Science Ltd.

17. Consiglio, W., Driscoll, P., Witte, M. and Berg, W. P. (2003). Effect of Cellular Telephone Conversations and other Potential Interference on Reaction Time in a Braking Response in Accident Analysis and Prevention, Vol. 35, Pages 495-500. Elsevier Ltd.

18. Curzon, P., Blandford, A., Butterworth, R. and Bhogal, R. (2002). Interaction Design Issues for Car Navigation Systems in Sharp, Chalk, LePeuple \& Rosbottom (Eds) Proceedings Volume 2 of the 16th British HCI Conference. British HCI Group.
19. Daimon, T. and Kawashima, H. (1996). New Viewpoints for Evaluation of In-Vehicle Information Systems: Applying Methods in Cognitive Engineering in JSAE Review, Vol. 17, Pages 151-157. Elsevier Science B.V.

20. Donmez, B., Boyle, L. Ng, Lee, J. D. and McGehee, D. V. (2006). Drivers Attitudes Toward Imperfect Distraction Mitigation Strategies in Transportation Research Part F Traffic Psychology and Behaviour, Vol. 9, Issue 6, Pages 387-398. Elsevier Ltd.

21. Drews, F. A., Pasupathi, M. and Strayer, D. L. (2004). Passenger and Cell-Phone Conversations in Simulated Driving in Proceedings of the Human Factors and Ergonomics Society 48th Annual Meeting, Pages 2210-2212. Department of Psychology, University of Utah.

22. Erp, J. B.F. van and Veen, H. A.H.C. van (2001). Vibro-Tactile Information Presentation in Automobiles. EuroHaptics 2001.

23. Gellatly, A. William (1997). The Use of Speech Recognition Technology in Automotive Applications. Faculty of the Virginia Polytechnic Institute and State.

24. Green, P. (2001). Variations in Task Performance Between Younger and Older Drivers: UMTRI Research on Telematics in Association for the Advancement of Automotive Medicine Conference on Aging and Driving, Southfield, Michigan.

25. Green, P. (1999). The 15-Second Rule for Driver Information Systems. Intelligent Transportation Society of America.

26. Hampton, P. and Langham, M. (2005). A Contextual Study of Police Car Telematics: The Future of In-Car Information Systems in Ergonomics, Vol. 48, No. 2, Pages $109-118$ Taylor \& Francis Ltd.

27. Hancock, P. A., Simmons, L., Hashemi, L., Howarth, H. and Ranney, T. (1999). The Effects of In-Vehicle Distraction on Driver Response During a Crucial Driving Maneuver in Transportation Human Factors, Pages 295 - 309. Lawrence Earlbaum Associates, Inc.

28. Hancock, P., Lesch, M. and Simmons, L. (2003). The Distraction Effects of Phone Use During a Crucial Driving Maneuver in Accident Analysis and Prevention, Vol. 35, Pages 501-514. Elsevier Science Ltd.

29. Harbluk, J. L. and Noy, Y. Ian (2002). The Impact of Cognitive Distraction on Drive Visual Behaviour and Vehicle Control in Transport Canada. Road Safety Directorate and Motor Vehicle Regulation Directorate.

30. Healey, J. A. and Picard, R. W. (2005). Detecting Stress During Real-World Driving Task Using Physiological Sensors in IEEE Trans. on Intelligent Transportation Systems, Vol. 6 , No. 2, Pages 156-166. ACM Press.

31. Hennesy, D. A. and Wiesenthal, D. L. (1997). The Relationship Between Traffic Congestion, Driver Stress and Direct Versus Indirect Coping Bebeviours in Ergonomics, Vol. 40, No. 3, Pages 348-361. Taylor \& Francis Ltd.

32. Ho, C. (2004). Using Spatial Warning Signals to Capture a Driver's Visual Attention in ICMI'04, October 13-15, State College, Pennsylvania, USA..

33. Ho, C., Tan, H. Z. and Spence, C. (2006). The Differential Effect of Vibrotactile and Auditory Cues on Visual Spatial Attention in Ergonomics, Vol. 49, No. 7, Pages 724-738. Taylor \& Francis Ltd.

34. Hulst, M. van der, Meijman, T. and Rothengatter, T. (2001). Maintaining Task Set Under Fatigue: A Study of Time-on-Task Effects in Simulated Driving in Transportation Research Part F: Traffic Psychology and Behaviour, Vol. 4, Issue 2, Pages 103-118. Department of Work and Organisational Psychology, University of Nijmegen.

35. Jonsson, I., Harris, H. and Nass, C. (2005). Thank you, I did not see that: In-Car Speech Based Information Systems for Older Adults. CHI 2005.

36. Jonsson, I., Nass, C., Endo, J., Reaves, B., Harris, H., Ta, J. Le, Chan, N. and Knapp, S. (2004). Don't Blame me I am Only the Driver: Impact of Blame in Late Breaking Results Paper. CHI 2004.

37. Kantowitz, B. H. (2000). In-Vehicle Information Systems: Premises, Promises, and Pitfalls in Transportation Human Factors, Vol. 2, No. 4, Pages 359-379. Lawrence Erlbaum Associates, Inc.

38. Klauer, S. G., Dingus, T. A., Neale, V. L. and Sudweeks, J. D. (2006). The Impact of Driver Inattention on Near-Crash/Crash Risk: An Analysis Using the 100-Car Naturalistic Driving Study Data.

39. Lai, J., Cheng, K., Green, P. and Tsimhoni, O. (2001). On the Road and on the Web: Comprehension of Synthetic and Human Speech While Driving in CHI 2001. IBM/UMTRI.

40. Lamble, D., Kauranen, T., Laakso, M. and Summala, H. (1999). Cognitive Load and Detection Thresholds in Car Following Situations: Safety Implications for Using Mobile Detection Thresholds in Car Following Situations: Safety Implications for Using Mobile
(Cellular) Telephones while Driving in Accident Analysis and Prevention, Vol. 31, Pages 617-623. University of Helsinki.

41. Lansdown, T. C. (2002). Individual Differences During Driver Secondary Task Performance: Verbal Protocol and Visual Allocation Findings in Accident Analysis and Performance: Verbal Protocol and Visual Allocation
Prevention 34, Pages 655-662. Elsevier Science Ltd.

42. Lansdown, T. C., Brook-Carter, N. and Kersloot, T. (2004). Distraction from Multiple InVehicle Secondary Tasks: Vehicle Performance and Mental Workload Implications in Ergonomics, Vol. 47, No. 1, Pages 91-104. Taylor \& Francis Group.

43. Lansdown, T. C., Brook-Carter, N. and Kersloot, T. (2002). Primary Task Disruption from Multiple In-Vehicle Systems in ITS Journal, Vol. 7, Pages 151-168. Taylor \& Franci Group

44. Lee, J. D., Caven, B., Haake, S. and Brown, T. L. (2001). Speech-based Interaction with Invehicle Computers: The Effect of Speech-based E-mail on Drivers Attention to the Roadway in Human Factors, Pages 631-640.

45. Lee, J. D., Gore, B. F. and Campbell, J. L. (1999). Display Alternatives for In-Vehicle and Sign Information: Message Style, Location, and Modality in Transportation Human Factors, Vol. 1, No. 4, Pages 347-375. Lawrence Erlbaum Associates, Inc.

46. Lee, J., Forlizzi, J. and Hudson, S. E. (2005). In-Vehicle Interfaces: Studying the Effectiveness of MOVE: A Contextually Optimized In-Vehicle Navigation System in CHI 2005, April, Pages 571-580. Human-Computer Interaction Institute and School of Design, Carnegie Mellon University.

47. Liu, Y. (2003). Effects of Using Head-Up Display in Automobile Context on Attention Demand and Driving Performance in Displays, Vol. 24, Issues 4-5, Pages 157-165. Elsevier B.V

48. Liu, Y. (2001). Comparative Study of the Effects of Auditory, Visual and Multimodality Displays on Drivers in Ergonomics, 2001, Vol. 44, No. 4, Pages 425-442. Taylor \& Franci Ltd.

49. Liu, Y. and Wen, M. (2004). Comparison of Head-Up Display (HUD) vs. Head-Down Display (HDD): Driving Performance of Commercial Vehicle Operators in Taiwan i International Journal of Human-Computer Studies, Vol. 61, Issue 5, Pages 679-697. Elsevier Ltd.

50. Liua, B. and Lee, Y. (2006). In-vehicle Workload Assessment: Effects of Traffic Situation and Cellular Telephone Use in Journal of Safety Research, Vol. 37, Pages 99-105. National Safety Council and Elsevier Ltd.

51. Ma, R. and Kaber, D. B. (2005). Situation Awareness and Workload in Driving While Using Adaptive Cruise Control and a Cell Phone in International Journal of Industrial Ergonomics, Vol. 35, Pages 939-953. Elsevier B.V.

52. Matthews, G., Sparkes, T. J. and Bygrave, H. M. (1996). Attentional Overload, Stress, and Simulate Driving Performance in Human Performance, Vol. 9, Pages 77-101. Lawrence Erlbaum Associates. 


\section{K. Bach et al.}

53. Mayer, K., Friedman, D. and Grenn, P. (2002). HUD Feedback to Minimize the Risk of Cellular Phone Use and Number Entry While Driving. University of Michigan Transporation Research Institute (UMTRI)

54. McCarley, J. S., Vais, M. J., Pringle, H., kramer, A. F., Irwin, D. E. and Strayer, D. L. (2004). Conversation Disrupts Change Detection in Complex Traffic Scenes in Human Factors, Vol. 46, No. 3, Pages 424-436. Beckman Institute, University of Illinois.

55. McElheny, M. Jean (2005). Multidimensional Warnings: Evaluating Curve Warning Stimuli in an On-Road Environment. Virginia Polytechnic Institute and State University.

56. McKnight, A. James and McKnight, A. Scott (1993). The Effect of Cellular Phone Use Upon Driver Attention in Accident Analysis \& Prevention, Vol. 25, Issue 3, Pages 259-265 Elsevier Science Ltd

57. Nass, C., Jonsson, I., Harris, H., Reaves, B., Endo, J., Brave, S. and Takayama, L. (2005). Improving Automotive Safety by Pairing Driver Emotion and Car Voice Emotion in $\mathrm{CHI}$, April 2-7, Portland, Oregon, USA. ACM Press.

58. Noy, Y. Ian, Lemoine, T. L., Klachan, C. and Burns, P. C. (2004). Task Interruptability and Duration as Measures of Visual Distraction in Applied Ergonomics, Vol. 35, Pages 207-213. Elsevier Ltd.

59. Parkes, A. M., Ashby, M. C. and Fairclough, S. F. (1991). The Effects of Different InVehicle Route Information Displays on Driver Behaviour. HUSAT Research Institute UK, The Technical University of Berlin, BMW AG of Munich, Germany.

60. Patten, C. J.D., Kircher, A., Östlund, J. and Nilsson, L. (2004). Using Mobile Telephones: Patten, C. J.D., Kircher, A., Ostlund, J. and Nilsson, L. (2004). Using Mobile Telephones:
Cognitive Workload and Attention Resource Allocation in Accident Analysis and Prevention, Vol. 36, Pages 341-350. Elsevier Ltd.

61. Patten, C. J.D., Kircher, A., Östlund, J., Nilsson, L. and Svenson, O. (2006). Driver Experience and Cognitive Workload in Different Traffic Environments in Accident Analysis and Prevention, Vol. 38, Pages 887-894. Elsevier Ltd.

62. Pauzié, A. (2002). In-Vehicle Communication Systems: The Safety Aspect in Injury Prevention, Vol. 8, Pages 26-29. BMJ Publishing Group Ltd.

63. Piechulla, W., Mayser, C., Gehrke, H. and König, W. (2003). Reducing Drivers in Transportation Research Part, Pages 233-248. Elsevier Ltd.

64. Recarte, M. A. and Nunes, L. M. (2000). Effects of Verbal and Spatial-Imagery Tasks on Eye Fixations While Driving in Journal of Experimental Psycology, Vol. 6, No.1, Pages 31 43. American Psychological Association, Inc.

65. Recarte, M. A. and Nunes, L. M. (2003). Mental Workload While Driving: Effects on Visual Search, Discrimination, and Decision Making in Journal of Experimental Psychology, Vol. 9, No. 2, Pages 119-137. American Psychological Association, Inc.

66. Recarte, M. Angel and Nunes, L. (2002). Mental Load and Loss of Control over Speed in Real Driving. Towards a Theory of Attentional Speed Control in Transportation Research Part F 5, Pages 111-122. Elsevier Science Ltd.

67. Redelmeier, D. A. and Tibshirani, R. J. (1997). Association Between Cellular Telephone Calls and Motor Vehicle Collisions in The New England Journal of Medicine, Vol. 336, No. 7. Pages 453-458. Massachusetts Medical Society, Publishing Division.

68. Richter, P., Wagner, T., Heger, R. and Weise, G. (1998). Psychophysiological Analysis of Mental Load During Driving on Rural Roads - A Quasi-Experimental Field Study in Ergonomics, Vol. 4I, No. 5, Pages 593-609. Taylor \& Francis Ltd.

69. Rimini-Doering, M., Manstetten, D., Altmueller, T., Ladstaetter, U. and Mahler, M. (2001). Monitoring Driver Drowsiness and Stress In A Driving Simulator in Driving Assesment 2001. The University of Iowa.

70. Rockwell, T. H. (1988). Spare visual capacity in driving - revisited: New empirical results for an old idea in Gale, A.G., et al. Ed.: Vision in Vehicles II, Pages 317-324. Elsevier Science, North Holland.

71. Rosenbloom, T. (2006). Driving Performance While Using Cell Phones: An Observational Study in Journal of Safety Research, Vol. 37, Pages 207-212. National Safety Council and Elsevier Ltd.

72. Salvucci, D. D. (2001). Predicting the Effects of In-Car Interfaces on Driver Behavior Using a Cognitive Architecture in CHI 2001, Vol. 3, No. 1, Page 120-127. ACM Press.

73. Salvucci, D. D., Boer, E. R. and Liu, A. (2001). Toward an Integrated Model of Driver Behavior in a Cognitive Architecture. Transportation Research Record.

74. Salvucci, D. D., Zuber, M., Beregovaia, E. and Markley, D. (2005). Distract-R: Rapid Prototyping and Evaluation of In-Vehicle Interfaces in In-Vehicle Interfaces. CHI 2005.

75. Schneider, M. and Kiesler, S. (2005). In-Vehicle Interfaces: Calling While Driving: Effects of Providing Remote Traffic Context in CHI 2005, April, Pages 561-569. Human-Computer of Providing Remote Traffic Context in CHI 2005, April, Pages 561-569.

76. Sodhi, M., Reimer, B., Cohen, J. L., Vastenburg, E., Kaars, R. and Kirschenbaum, S. (2002). On-road Driver Eye Movement Tracking Using Head-Mounted Devices in ETRA'O2 New Odeans Louisiana USA.

77. Somervell, J., McCrickard, D. Scott, North, C. and Shukla, M. (2002). An Evaluation of Information Visualization in Attention-Limited Environments in IEEE TCVG Symposium on Visualization. The Eurographics Association.
78. Stanton, N., Young, M. and McCaulder, B. (1997). Drive-by-wire: The case of driver workload and reclaiming control with adaptive cruise control in Safety Science Vol. 27, No. 2, Pages 149-159. Elsevier Science Ltd.

79. Strayer, D. L. and Drews, F. A. (2006). Multi-tasking in the Automobile in Applied Attention: From Theory to Practice.

80. Strayer, D. L. and Johnston, W. A. (2001). Driven to Distraction: Dual-Task Studies of Simulated Driving and Conversing on a Cellular Phone in Psychological Science, Vol. 12, No. 6, Pages 462-466. American Psychological Society.

81. Strayer, D. L., Cooper, J. M. and Drews, F. A. (2004). What do Drivers Fail to See when Conversing on a Cell Phone? in Proceedings of the Human Factors and Ergonomics Society 48th Annual Meeting, New Orleans, Louisiana, USA, Pages 2213-2217. Human Factors and Ergonomics Society.

82. Strayer, D. L., Drews, F. A. and Crouch, D. J. (2006). A Comparison of the Cell Phone Driver and the Drunk Driver in Human Factors, Vol. 48, No. 2, Pages 381-391. Human Factors and Ergonomics Society.

83. Strayer, D. L., Drews, F. A. and Johnston, W. A. (2003). Cell Phone-Induced Failures of Visual Attention During Simulated Driving in Journal of Experimental Psychology, Vol. 9 , No. 1, Pages 23-32. American Psychological Association, Inc.

84. Strayer, D. L., Drews, F. A., Crouch, D. J. and Johnston, W. A. (2002). Why do Cell Phone Conversations Interfere with Driving? in W. R. Walker and D. Herrmann (Eds.) Cognitive Technology: Transforming Thought and Society. McFarland \& Company Inc.

85. Tijerina, L., Johnston, S., Parmer, E., Winterbottom, M. D. and Goodman, M. (2000) Driver Distraction with Wireless Telecommunications and Route Guidance Systems. U. S. Department of Transportation, National Highway Traffic Safety Administration.

86. Trbovich, P. and Harbluk, J. L. (2003). Cell Phone Communication and Driver Visua Behavior: The Impact of Cognitive Distraction in CHI 2003, April 5-10, Ft. Lauderdale, Florida, USA.

87. Tsimhoni, O. and Green, P. (2001). Visual Demand of Driving and the Execution of Display-Intensive, In-Vehicle Tasks in Proceedings of the Human Factors and Ergonomics Society 45th Annual Meeting 2001.

88. Tsimhoni, O., Green, P. and Watanabe, H. (2001). Detecting and Reading Text on HUDS Effects of Driving Workload and Message Location in 11th Annual ITS America Meeting Miami, FL. University of Michigan Transportation Research Institue (UMTRI).

89. Tsimhoni, O., Smith, D. and Green, P. (2004). Address Entry While Driving: Speech Recognition Versus a Touch-Screen Keyboard in Human Factors, Vol. 46, No. 4, Pages 600-610. Human Factors and Ergonomics Society.

90. Tsimhoni, O., Yoo, H. and Green, P. (1999). Effects of Visual Demand and In-Vehicle Task Complexity on Driving and Task Performance as Assessed by Visual Occlusion. University of Michigan Transportation Research Institue (UMTRI)

91. Törnros, J. and Bolling, A. (2006). Mobile Phone Use - Effects of Conversation on Mental Workload and Driving Speed in Rural and Urban Environments in Transportation Research Part F 9, Pages 298-306. Elsevier Ltd.

92. Törnros, J. E.B. and Bolling, A. K. (2005). Mobile Phone Use - Effects of Handheld an Handsfree Phones on Driving Performance in Accident Analysis and Prevention, Vol. 37, Pages 902-909. Elsevier Ltd

93. Uang, S. and Hwang, S. (2003). Effects on Driving Behavior of Congestion Information an of Scale of In-Vehicle Navigation Systems in Transportation Research Part C, Vol. 11 Pages 423-438. Elsevier Ltd.

94. Verwey, W. B. and Veltman, H. A. (1999). Detecting Short Periods of Elevated Workload: A Comparison of Nine Workload Assessment Techniques in Journal of Experimental Psychology: Applied, Vol. 2, No. 3, Pages 270-285. American Psychological Association, Inc.

95. Verwey, W. B. and Zaidel, D. M. (2000). Predicting Drowsiness Accidents from Personal Attributes, Eye Blinks and Ongoing Driving Behaviour in Personality and Individual Differences, Vol. 28, Pages 123- 142. Elsevier Science Ltd.

96. Wierville, W. A. (1993). Visual Sampling of In-Car Displays in A. G. Gale, et al. (Eds.) Vision in Vehicles, pp. 271-280. Elsevier Science Ltd.

97. Wittmanna, M., Kiss, M., Gugg, P., Steffen, A., Fink, M, Pöppel, E. and Kamiya, H. (2005). Effects of Display Position of a Visual In-Vehicle Task on Simulated Driving in Applied Ergonomics, Vol. 37. Elsevier Ltd.

98. Zajicek, M. and Jonsson, I. (2005). Evaluation and Context for In-Car Speech Systems for Older Adults in CLIHC

99. Zwahlen, H. T., Adams, C. and DeBald, D. (1988). Safety Aspects of CRT Touch Panel Controls on Automobiles in Gale, A.G., et al. Ed.: Vision in Vehicles II, Pages 335-344. Elsevier Science, North Holland.

100. Åkesson, K. and Nilsson, A. (2002). Designing Leisure Applications for the Mundane CarCommute in Personal and Ubiquitous Computing, Vol. 6, Pages 176-187. Springer-Verlas London 